\title{
Preparations for implementation of RDA in New Zealand public libraries
}

\author{
by
}

\section{Chloe Samantha Turner}

Submitted to the School of Information Management,

Victoria University of Wellington

In partial fulfilment of the requirements for the degree of

Master of Library and Information Studies

\section{June 2010}




\section{ACKNOWLEDGEMENTS}

I would like to thank my supervisor, Dan Dorner, for all his time, support and advice. I am grateful for his answering of my panicked questions, telling me that I had it right all along and for his many readings of my various drafts, all returned with helpful and insightful comments. 
Abstract

1.0 Introduction

2.0 Research problem

3.0 Research questions

4.0 Limitations and delimitations

4.1 Limitations

4.2 Delimitations

5.0 Definition of relevant terms

6.0 Literature review

$\begin{array}{lll}6.1 & \text { Introduction } & 7\end{array}$

6.2 Resource Description and Access 8

6.3 RDA descriptive 8

$\begin{array}{lll}6.4 & \text { Anti-RDA } & 10\end{array}$

6.5 AACR2 11

6.6 AACR2 viewpoint articles 11

$\begin{array}{lll}6.7 & \text { AACR2 implementation studies } & 14\end{array}$

6.8 Change management in libraries and other fields 16

$\begin{array}{ll}6.9 \text { Conclusion } & 19\end{array}$

$\begin{array}{ll}7.0 \text { Research description } & 19\end{array}$

8.0 Research design 20

8.1 Method of gathering data 20

8.2 Research population 21

8.3 Ethical considerations 22

8.4 Interview procedure 23

8.5 Treatment of data 24

$\begin{array}{ll}9.0 \text { Research question } & 25\end{array}$

9.1 Sub-question one 26

9.2 Sub-question two 28

$\begin{array}{lll}9.3 & \text { Sub-question three } & 29\end{array}$

9.4 Sub-question four $\quad 32$

10.0 Research objective 36

\begin{tabular}{ll}
10.1 & Suggestions for further research \\
\hline
\end{tabular}

11.0 References $\quad 43$

12.0 Appendices $\quad 48$

12.1 Participant information sheet 48

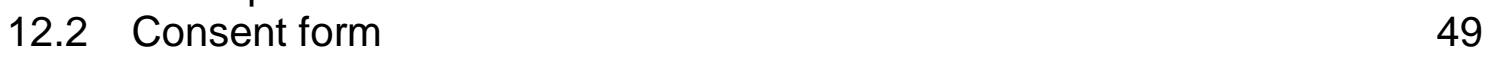

12.3 Interview guide $\quad 50$ 


\section{ABSTRACT}

This study examines how New Zealand public libraries will implement the new cataloguing standard of RDA by investigating what preparations for implementation they are making.

This study uses a qualitative methodology. The researcher interviewed seven Heads of Cataloguing from public libraries in the lower North Island. These interviews were then analysed to bring out common themes and any differences between interviews.

Public libraries in New Zealand are not currently planning on implementing RDA. This will come in the near future when the Library of Congress and then the National Library release their decisions on the implementation of RDA

As the last cataloguing change was over thirty years ago, public libraries are likely to be uncertain about what they will need to do to implement this change and how it will affect them.

This research will be useful in that it will allow other New Zealand public libraries to see how various libraries are preparing for RDA. This information can then be used to aid in their own decision-making processes.

Keywords: Implementation, preparations, public library, Resource Description and Access, RDA 


\subsection{INTRODUCTION}

This research project is a study about the forthcoming implementation of Resource Description and Access (RDA), and the preparations that libraries are making for RDA. This research specifically looks at the preparations for implementation of RDA that public libraries in New Zealand are making.

As RDA is not due to be released in its final format until June 2010, it is perhaps not surprising that there is a lack of research on this subject in the library and information management literature. This research aims to find out how New Zealand public libraries are planning on implementing the incoming cataloguing standard of RDA by finding out what preparations libraries are making for RDA, what would enable libraries to make preparations, what is preventing or aiding libraries to make preparations for the implementation of RDA, and how the implementation of RDA compares with the implementation of the Anglo-American Cataloguing Rules $2^{\text {nd }}$ edition (AACR2).

Cataloguing across the world is in a state of flux with the new standard of RDA in the wings. As the last major change in cataloguing standards was AACR2 in 1978, many public libraries will want to know how other public libraries plan on implementing RDA, so that they themselves can follow suit, or take another route in their implementation (1979, 321-339.).

This research used a qualitative methodology to gather data by interviewing the Head of Cataloguing (or the person with an equivalent job title) at seven 
New Zealand public libraries in the lower North Island. The data gathered from these interviews was then analysed to bring out the themes. These themes were then used to answer the research question and objective.

\subsection{RESEARCH PROBLEM}

As there have been no major changes in cataloguing standards since the late 1970s, what public libraries in New Zealand will need to do to prepare to implement the incoming standard of RDA is very much up in the air. Some of the possible issues relating to RDA could be budgetary concerns of how much RDA will cost, technological concerns of whether the library's current library management system (LMS) will be able to cope with the introduction of RDA, or perhaps human resources concerns such as staff training.

In order to answer these valid concerns, it is important to find out what preparations for the implementation of RDA public libraries in New Zealand are making. This understanding will in turn inform public libraries in New Zealand of what preparations other libraries are making. This data about what preparations are being made will then provide public libraries with more information to enable them to make their own decisions on what preparations for the implementation of RDA they should be making.

RDA is the new cataloguing code intended to replace AACR2 and is due for release in June 2010 (Joint Steering Committee for Development of RDA, 2005). The release date was updated on 23 June 2010 with the 
announcement of the availability of the online database format of RDA, called the RDA Toolkit (American Library Association, Canadian Library Association, \& Chartered Institute of Library and Information Professionals, 2010b). The Toolkit is intended to be the main format of RDA; however the publishers of the RDA Toolkit will also make it available as a paper copy, to make sure that it reaches the greatest amount of people possible (American Library Association, Canadian Library Association, \& Chartered Institute of Library and Information Professionals, 2010d). Both the online toolkit and the paper copy will also be available in translated versions. RDA is based on the foundations of Functional Requirements for Bibliographic Records (FRBR), which has the primary tasks of enabling library users to find, identify, select and obtain a particular information resource (Joint Steering Committee for the Development of RDA, 2010).

As AACR2 was published over thirty years ago, it has been steadily getting more and more out of date and unworkable. When AACR2 was first published, the Internet had not been invented and compact discs were not even thought of at that time. Although updates were published for AACR2, it was always behind the times and scrambling to catch up, cataloguingwise, with the plethora of digital formats that were being created. Therefore, the Joint Steering Committee (the body that publishes AACR2) decided that the cataloguing code of AACR2 needed a complete overhaul.

As of October 2007, four national libraries have agreed to implement RDA the British Library, the Library and Archives Canada, the National Library of 
Australia and the Library of Congress. However, the three United States national libraries (the Library of Congress, the National Agricultural Library and the National Library of Medicine) are testing RDA with a view to whether they will implement it or not (Joint Steering Committee for the Development of RDA, 2010). This indecision by the Library of Congress, along with the silence from OCLC on its plans regarding the implementation of RDA have led many in the cataloguing community to wonder if RDA will actually be implemented.

Due to the relative newness of RDA, which has only been around with the name of RDA since 2005, perhaps it is unsurprising that there is not a substantial amount of research in the library and information management sector, and that what articles are available, tend to be either descriptive of the new standard, or opinion pieces in support or against the implementation of RDA (Joint Steering Committee for the Development of RDA, 2010). This lack of literature shows that there is a need for more research to be done on this topic. Once RDA has been released in its final format, libraries across the world can begin to examine this new standard and start to make plans of whether and how to proceed with their implementation. As RDA is due to be released in June 2010, this is an appropriate moment for this study to be carried out.

With RDA being tested by the three American national libraries it is time for New Zealand to think on how it will implement RDA (Library of Congress, 2010). This study will enable libraries across the country to see what 
preparations are being undertaken, and to inform their choices about what they may wish to do.

\subsection{RESEARCH QUESTIONS}

The objective of this research is to discover how public libraries in New Zealand plan on implementing the new cataloguing standard of Resource Description and Access (RDA).

Research question:

- How are public libraries in New Zealand planning on implementing RDA?

Sub-questions:

- What preparations for implementation of RDA are New Zealand public libraries making?

- What would enable New Zealand public libraries to make preparations for RDA?

- What are the barriers to and enablers for implementation of RDA for New Zealand public libraries?

- How does the implementation of RDA compare with the implementation of the Anglo-American Cataloguing Rules $2^{\text {nd }}$ edition (AACR2)? 


\subsection{LIMITATIONS AND DELIMITATIONS}

\subsection{LIMITATIONS:}

The size of this research is the foremost limitation. This research can hope to gain an overview of how the particular public libraries involved in this research plan to implement RDA, but due to the small nature of the sample size, it is unlikely that the findings of this study will be transferable to other sorts of libraries or other countries.

\subsection{DELIMITATIONS:}

This study has been limited to heads of cataloguing; as the people in this role will know what direction their department is heading in, what changes are on the horizon, and how they will prepare for these changes.

This research has been also limited to the Lower North Island area due to the cost of travel.

\subsection{DEFINITION OF RELEVANT TERMS}

AACR2 - Anglo American Cataloguing Rules $2^{\text {nd }}$ edition RDA - Resource Description and Access, due to replace AACR2 FRBR - Functional Requirements for Bibliographic Records, the basis of RDA 


\subsection{LITERATURE REVIEW}

\subsection{INTRODUCTION}

As the final version of the cataloguing standard due to replace AACR2 is not due for final release until June 2010, it is hardly surprising that no articles regarding the implementation of RDA were able to be found. The articles that were found fell into two categories, those that described RDA - what it contained, what it proposed to do, its structure etc., and viewpoint articles that agree that it is time for a change, but that believe RDA does not go far

enough, or is still based in the past. It is the aim of the literature review to find literature on the preparations for implementation of RDA and, comparatively, on the preparations for implementation of AACR2.

Being the first major cataloguing change in recent history, the implementation of AACR2 was also researched, but once again, articles fell into two categories - viewpoint articles, or implementation case studies. These will be discussed in the next section. The reason for the lack of research articles was judged to be that of the Library and Information Management (LIM) profession having not yet gained full momentum in producing concrete research for and about the library profession. 


\subsection{RESOURCE DESCRIPTION AND ACCESS}

RDA is scheduled to replace AACR2, and represents a major shift in cataloguing thinking, from the point of view of the cataloguer, to the point of view of the library user, by making it easier for the user to find library items. RDA is based on Functional Requirements for Bibliographic Records (FRBR), which contains the concept of entities, relationships and attributes (Joint Steering Committee for the Development of RDA, 2010). FRBR has the primary tasks of aiding the user in finding, identifying, selecting and obtaining a particular information resource (Joint Steering Committee for the Development of RDA, 2010). RDA is designed for the digital world, in that it will cope better with digital formats, and enable cataloguers to look in one place, not in several chapters to describe an information resource (Joint Steering Committee for Development of RDA, 2005). RDA will also primarily be a web tool, unlike AACR2, which is mainly a printed document, with an online access version (American Library Association, Canadian Library Association, \& Chartered Institute of Library and Information Professionals, 2006b, 2006c; Joint Steering Committee for the Development of RDA, 2010).

\subsection{RDA DESCRIPTIVE}

This and the below section describe the literature found on the incoming standard of RDA. The descriptive articles give details of the structure of RDA and visualise some of the impacts that RDA might have on the library world. The anti-RDA section contains some of the objections to RDA, ranging from its relevance to non-librarians, to the amount of change from AACR2. 
RDA is made up of two parts - Part A (description) and Part B (access point control). Before it was reduced to two parts, it was a tri-part structure with Part I (description), Part II (relationships) and Part III (authority control). Part I and II have been combined into Part A and Part III is now Part B (Moore, 2006, 12-16.). Jones and Carr (2007, 281-289.) comment on levels of detail, transcription, inaccuracies and the 'rule of three', but still describe the structure as being in three parts. Needleman $(2008,233-234$.$) gives$ details of the two sections with their current titles of attributes and relationships, along with the chapters contained within each.

Moore (2006, 12-16.) and Adamich (2008, 64-69.) both briefly discuss the impact RDA may have on libraries. Moore says one of the major effects of RDA will be in cataloguers learning the new rules. Moore also makes the point that it is not just librarians that will be affected, but it is also the vendors of the library systems that will have to adapt to the change as well. Moore acknowledges that as with every new change, there will be a cost, whether it is financial or in human resources. Adamich takes a different tack and looks at the cost to school libraries. Adamich believes that the cataloguing process will not change greatly, as teacher librarians already modify records they receive from elsewhere. However, there will be a change in the types of information resources they will catalogue, with items such as streaming video or websites being added. Teacher librarians will also start using other bibliographic standards, such as DublinCore to present metadata in ways that go beyond that of the generic library. 
Needleman $(2008,233-234$.) poses three of the many questions that librarians may want answered - what might the implications be for current and future library system vendors; how many will actually adopt it, and will it just be the library community that does; and what are the implications for existing standards like AACR2 and MARC?

\subsection{ANTI-RDA}

There are a number of criticisms regarding RDA. Tennant $(2007,25$. believes that RDA is still stuck in the past with too many legacy approaches. Coyle and Hillman (2007) say that one of these concepts is main entry (which Conners $(2008,85-97$.) agrees with) and another is the fact that RDA data will still correspond with AACR2 records, therefore not being a complete break with the past. Coyle and Hillman also take the point further and say that new formats are still being catalogued as if they were books, something that needs to change.

One of the aims of RDA was to be relevant to more than just the LIM community (Joint Steering Committee for the Development of RDA, 2010). However, with most of the reviewers being cataloguers, the suggestions from outsiders have been largely drowned out. If cataloguers are finding RDA too complex, with confusing examples, how are outsiders to the LIM community supposed to adopt this standard (Coyle \& Hillman, 2007; Gorman, 2007, 6465. ; Tennant, 2007, 25.)? Gorman (Gorman, 2007, 64-65.) objects to the structuring of RDA, which he believes to not be ordered sensibly. 


\subsection{AACR2}

AACR2 is a cataloguing standard used by a large part of the world to build their library catalogue. As the AACR website says "[t]he rules cover the description of, and the provision of access points for, all library materials commonly collected at the present time" (American Library Association, Canadian Library Association, \& Chartered Institute of Library and Information Professionals, 2006a). AACR2 is based on the International Standard of Bibliographic Description (ISBD). Part I is used for description of the item and Part II for the creation of access points (American Library Association et al., 2006c).

\subsection{AACR2 VIEWPOINT ARTICLES}

In this and the below section, the focus shifts to the current cataloguing standard of AACR2. Whilst the viewpoint articles list the changes along with the positive benefits of AACR2, the implementation studies give a range of suggestions on how a library might go about implementing AACR2.

Gorman (1978, 620-621.) argued against the delay of implementation of AACR2 as he said this left cataloguers with a code that did not match the practice of cataloguing. Osborn $(1979,301-304$.) believed the introduction of multiple levels of cataloguing was a brilliant addition and that level one cataloguing (author and title only) with modifications would suit most libraries. Osborn thought that as many libraries had a cataloguing backlog, they should think hard before deciding to catalogue at a higher level. Osborn (1979, 301-304.) and Simonton (1979, 321-339.) listed the major 
changes in AACR2, with Simonton also describing the structure. Paralleling what seems to be happening for RDA, AACR2 was not universally welcomed. Buckle (1986, 1-5.) described the products and services that the British Library made available to aid libraries in their conversion to AACR2.

Recognising that the implementation of AACR2 could be costly, not just for itself, but for the whole LIM community, Simonton (1979, 321-339.) described the Library of Congress' (LC) policy of 'gradual adoption' by publishing a list of headings that are not in complete agreement with AACR2, but are judged to be 'compatible'. These compatible headings would continue to be used after the pushed-back implementation date of 1981 . Where the changes were only minor, they would be adopted only for new headings.

As the National Library of Australia used cataloguing cards from the British Library and the Library of Congress as well as those they produced themselves, Fullerton $(1979,13-25$.$) supported the implementation of$ AACR2, as this would reduce the time and cost spent in reconciliation. Fullerton listed the changes in AACR2 and how they would affect the National Library.

Gorman (1987, 110-112.) believed that if cataloguing rules do not change, they stagnate and become ever more idiosyncratic as the organisations which cling to them have to find ways of coping with new materials. These idiosyncrasies then become a barrier to co-operation - this is what happened 
before the introduction of AACR2. Gorman regarded the introduction of AACR2 as a great help to the cataloguing profession as it replaced all the fragmented systems, did away with superimposition, introduced ISBD and became a truly international code. However, as Michael Gorman was one of the editors charged with revising AACR into AACR2 in 1978, this is perhaps not surprising (Joint Steering Committee for Development of RDA, 2009).

Gorman (1978, 620-621.) argued that AACR did not match current library practices. This assertion can also be applied to today's current cataloguing standard of AACR2. AACR2 has become outdated and was not designed to cope with today's digital world, a problem that RDA has been designed to fix (Joint Steering Committee for the Development of RDA, 2010). Paralleling Buckle's (1986, 1-5.) description of services provided to libraries by the British Library, there is a high likelihood that national libraries worldwide and possibly the Joint Steering Committee will be providing assistance for libraries to help them through the transition to RDA. The changes listed by Fullerton $(1979,13-25$.$) have similarities in the changes to RDA. For$ example, changes in physical description in AACR2 and the divergence between form of content and form of carrier, or changes to the form of entry, such as using 'audio' instead of 'sound'. As RDA is designed to be compatible with AACR2, it may not necessarily be as big a change as changing to AACR2 was (Joint Steering Committee for Development of RDA, 2005). Co-operation between libraries still plays a role today, as many libraries upload or download catalogue records to or from larger 
organisations. If these libraries were not all using the same cataloguing standard, this sharing of data would not work.

\subsection{AACR2 IMPLEMENTATION STUDIES}

Elrod $(1979,29-32$.$) listed five situations that a smaller library might find$ themselves in and gave suggestions on what they should do about the end of superimposition and the introduction of AACR2. These suggestions ranged from using guide cards, closing the card catalogue, updating computer records or adjusting MARC records.

Woodruff Library at Emory University in Atlanta, Georgia also carried out a study and found that $31 \%$ of their headings would change under AACR2, but by accepting LC's decisions on compatible headings, this was reduced by half to $15 \%$. Woodruff Library suggested three ways that the change to AACR2 could be made - interfiling, modifying headings, or a mixture of the two. They decided to only make a split file (containing 'see also' card entries) for corporate names, and files would only be split if they involved a major change (Kline \& Taylor, 1980, 209-213.)

Once AACR2 came out, libraries worried about how to implement it and what to do with their card catalogues. Most followed LC and waited until 1981 to implement the new code. McIver $(1985,117-127$.$) found that often$ small and medium libraries chose to interfile the old with the new, while larger libraries either chose to create a new card catalogue and connect it 
with the old one, or to create a new AACR2-compliant catalogue and completely freeze the old one.

Moving from the technical side to the human resources side, Spangen (1986, 1-6.) described how the Nordic countries educated their cataloguers for the introduction of AACR2. Most used a course and a book of examples and some used an orientation or a correspondence course. Libraries wanted to know what to do with their card catalogues. Hepfer and Hepfer $(1987,19-$ 25.) say that no one implementation scheme was used over and above any other, but that libraries made their own individual choices. As suggested in Kline and Taylor (1980, 209-213.),one method used was interfiling, but other libraries chose to freeze their old catalogue and start a new AACR2compliant card catalogue. Whatever method libraries used, neither service staff nor the public seemed to notice the change. With card catalogues becoming a thing of the past when libraries changed from AACR to AACR2, there are not so many similarities between the change to AACR2 and the change to RDA.

As RDA is backwards compatible (Joint Steering Committee for the Development of RDA, 2010), instead of worrying how or whether to update their card catalogues, many libraries are likely to just switch from one set of rules to another, and only update old records if there is a need to change them. This switching between cataloguing codes (RDA in the near future, and AACR2 in the past) indicates a likely similarity between the two implementations. As many libraries decided to freeze their old card 
catalogue and start afresh with AACR2, this too will be done by libraries implementing RDA, but this time with computer records instead of card catalogues.

Just as Elrod (1979, 29-32.) suggested that one of the things libraries may need to do is to update their MARC records, this time around this also needs to happen. The current MARC21 is not completely compatible with the FRBR basis of RDA. One example of this is the relationships between works, expressions, manifestations and items in RDA, which do not have a match in the current MARC standard (Hillman, 2009). However, whether MARC gets changed or updated to fit better with RDA and FRBR, or whether some other standard gets used in its place is still under debate, and is not the focus of this research.

As with the change to AACR2, it is to be expected that libraries will wait to see how larger institutions handle their implementation of RDA and then follow along. As one of the goals of RDA is to make library items easier to find, it is hoped that users of the library catalogue will notice a change, unlike what happened with AACR2.

\subsection{CHANGE MANAGEMENT IN LIBRARIES AND OTHER FIELDS}

A number of the articles dealing with change management in libraries are case studies of how a particular library dealt with a particular change that they were going through. Ferguson $(2007,524-530$.$) talks about four$ changes that happened at the libraries at the University of Hong Kong with 
respect to five people factors, being different people react differently to change, people want to know what is likely to affect them, dealing with change often takes people through a 'loss curve', expectations management, and dealing with fear towards the change. Ferguson then discusses how each change related to one of these people factors.

Wells $(2007,450-459$.) discusses how the library at the University of New South Wales handles the challenges of budget cuts and technological advances to remain relevant. Staff are involved in the change, from consultation on the future direction of the library, to electing 'change champions'.

La Trobe University brought in themes of preparation, planning, leadership, support, communication, managing resistance and evaluation of the change to guide them through their organisational change (Paton, Beranek, \& Smith, 2008, 87-103.).

Merewood and Philipp (2001, 36-40.) examine how Boston Medical Centre managed their change of becoming one of the small number of Baby Friendly accredited hospitals in the United States (Baby-Friendly USA, 2010). A strategy for change was created, which included formation of a task force to oversee the change process and the re-writing of policies. A lot of noise was made about the change, ensuring that all levels of staff knew about it. Staff involved with newborns were trained in the new procedures, and all other staff attended educational sessions, ensuring that they knew what the 
change was, why it needed to happen and the benefits of the change. New mothers were also educated about the benefits of breastfeeding and provided with support. This article also discusses the major obstacle that needed to be overcome - moving from receiving free or heavily discounted infant formula to paying a reasonable market price.

Chien, Su and Su (2002, 252-259.) discuss how a large Taiwanese manufacturing company implemented a customer satisfaction programme. In the pilot phase, information about other customer satisfaction plans was gathered, the vision and goals were set, top management support was gained, and employees were informed of the change, and why it needed to happen. In the promotion phase, awareness of the change continued to be built, each business unit set up its own implementation taskforce, along with an overall committee, and regular meetings were held to track progress.

For an organisational change, such as from AACR2 to RDA, to succeed, a number of factors need to be taken into account. From the case studies above, it can be seen that many of the aspects described above fall under the heading of people factors. This shows that how the employees of an organisation feel about the change and how involved they are in making the change happen has a great impact on whether the change will succeed or fail. The case studies also show that having a good change management plan and top management support is not enough to guarantee a successful change. 


\subsection{CONCLUSION}

Given the doubts expressed in the literature, it is unlikely that RDA will be implemented immediately once it is out, especially since LC did not implement AACR2 until 1981, two years after it was released. Much of the literature around describes what RDA contains, with a few touching on implications it might have. However, a vocal section believes that RDA will not succeed, as it is not enough of a break with the past. More literature was available on the implementation of AACR2 (the other major cataloguing change in recent history), but these were mainly viewpoints on how headings would be changed or how what methods particular libraries used to update their card catalogues.

\subsection{RESEARCH DESCRIPTION}

This research takes a qualitative approach to discover how New Zealand public libraries are preparing for RDA, what would facilitate libraries to make preparations, what is helping and what is hindering libraries from implementing RDA, and how the implementation of RDA compares with the implementation of AACR2, the previous major catalogue change.

At the moment, as RDA has not been formally released in its final format, it is reasonable that no formal research has been completed on preparations for implementation of this new cataloguing standard. This study aims to discover what preparations New Zealand public libraries are making for the implementation of RDA. As this study is investigating a topic about which 
not a lot is known, it is necessary to explore this topic using qualitative methodology.

Qualitative research aims to collect complex data through methods such as ethnographic studies, focus groups, or interviews. These data collection methods gather the views and opinions of the subject, which are then analysed to discover the meaning behind the words, whilst still keeping the context intact. This data and the resulting analysis are then used to develop a theory.

Data for this research project was gathered through the medium of semistructured interviews with Heads of Cataloguing at public libraries in New Zealand. Interviews were conducted with reference to the interview guide, which was used for all interviews. Once the interviewees had checked the transcripts of the interviews, coding of the transcripts could be started. From the coding of the transcripts, categories emerged from the data. Once all of the interview transcripts were coded, the interviews were compared to one another, in order to bring to light any similarities or differences.

\subsection{RESEARCH DESIGN}

\subsection{METHOD OF GATHERING DATA}

The main method of gathering data was focused interviews, where openended questions are used to gather views and opinions of the interviewee 
(Bryman, 2008, 748.). The interviews were carried out in a semi-structured format, enabling the researcher to tailor the questions to each interviewee, or to delve deeper into interesting areas brought up by the interviewee.

Where it was geographically feasible, the interviews were carried out face to face; otherwise the interviews were carried out either through instant messaging using Skype or by e-mail.

\subsection{RESEARCH POPULATION}

Interviews were carried out in seven separate public libraries, each in the lower North Island. As interviews were the preferred method of data collection, an initial convenience sample of public libraries in the Greater Wellington area was carried out, as the researcher would be able to easily travel to these libraries to interview the Head of Cataloguing face to face. Due to lack of responses, the sampling area was widened to the Lower North Island area, with libraries of varying sizes chosen at random. However, moving outside the Greater Wellington area meant that interview techniques other than face-to-face interviews had to be implemented.

In each of the public libraries, the Head of Cataloguing (or applicable person carrying out this role) was approached and asked if they were willing to participate in this study. As RDA is not due for final release until June 2010 , it was felt that the person responsible for making implementation plans and setting policy regarding RDA was the appropriate interview subject. 


\subsection{ETHICAL CONSIDERATIONS}

This research project was designed and carried out in accordance to meticulous ethical standards. As human subjects were involved, it was necessary to gain ethical approval from the Human Ethics Committee at Victoria University of Wellington. The research proposal was submitted for approval on the $25^{\text {th }}$ of February 2010, and was accepted subject to minor revisions on the $5^{\text {th }}$ of March 2010.

The interviewees were informed about the nature and purpose of the research through an information sheet, which was provided before the interview. The information sheet provided contact details of the researcher and the supervisor if the interviewee had any questions or wished for further information. The consent form was signed prior to the interview and all interviewees were informed that they could withdraw for any reason from the research project prior to coding of interviews starting.

In order to ensure the privacy of the individuals and organisations involved in this research project, certain names and identifying details have been removed. As another consideration, a large geographic area was chosen for the sampling area, although only a small number of interviews took place. Access to the research data (including the written or electronic information) was limited to the researcher and the supervisor. 
Participants were given the opportunity to check their interview transcripts in order to check that the transcription was accurate and that their opinions had not been distorted in any way. As specified in the research proposal submitted to and accepted by the Human Ethics Committee, audio files of the interviews will be deleted upon the completion of this project.

\subsection{INTERVIEW PROCEDURE}

To get the greatest amount of data, and the richest data possible, interviews were chosen as the most appropriate data collection method. Qualitative interviews aim to discover the interviewee's opinions and point of view. This type of interview also allows the interviewee to digress from the question at hand and bring up new material that they think is relevant, which the researcher can then follow up with further questions that may not be in the interview guide. Qualitative interviews are also very flexible, in that the wording or the order of questions can be changed to suit the interviewee.

In all interviews, the same interview guide was used. Interview guides are valuable, as they ensure conformity between interviews and that all questions are asked of all people. However, for a semi-structured interview guide, there is no strict emphasis on the wording or ordering of questions, they are free to be changed to suit each interviewee, as long as the meaning stays the same. This type of interview guide also allows the researcher to ask more probing questions and gives the researcher the ability to respond to areas of interest brought up by interviewees by asking further questions. 
Three face-to-face interviews were undertaken, along with two e-mail interviews and two interviews using the instant messaging function of Skype. Where it was reasonable to travel for a face-to-face interview, this was done; otherwise alternative means were arranged with the interviewees. As Skype is a popular computer programme used to keep in contact with friends or family members overseas, this was the preferred alternative of the two offered if the interviewee was too geographically distant. If the interviewee was both geographically distant, and did not have access to Skype, or some other form of instant messaging service, or this was not convenient for the interviewee, then the interview guide was e-mailed to the interviewee.

\subsection{TREATMENT OF DATA}

As the interviews were completed, the interview data was transcribed. It was at this stage that any personal or identifying information was removed; as it was thought to remove it as soon as possible was the better course. This information included personal names, names of organisations, colleagues, and cities or of library management systems. This last one was only removed where requested by the interviewee on checking of their transcript.

Transcription of each interview was done as soon as possible after the interview, so that the content of the interview was still fresh in the mind of the researcher. This meant that interviews were being transcribed before all of the interviews were completed. 
The data from the interviews was analysed using a method called qualitative content analysis. Qualitative content analysis is a way of analysing rich data, such as interviews, in order to find the meanings behind the words. This technique lets categories emerge from the data instead of being precoded. However, the words themselves are not the only thing of importance. It is also important to understand the context in which the words appear as well. For this research project, interviews were not pre-coded; this was in order to let coding categories become apparent with no preconceptions.

Each interview was analysed separately, then the responses to each question were collated in preparation for analysis. This was done to allow for comparisons between interviews to be made and also to draw out any common patterns or themes from the data, or any major differences between interviews. This interview analysis would then determine what conclusions could be drawn from this research.

\subsection{RESEARCH QUESTION}

- How are public libraries in New Zealand planning on implementing RDA?

This overall research question will be answered by collecting the results found for the four following sub-questions. As the research question and the research objective are the same, both will be answered in the research objective section. 


\subsection{SUB-QUESTION ONE}

- What preparations for implementation of RDA are New Zealand public libraries making?

Most of the libraries interviewed definitely plan to implement RDA at some point in the future. One library interviewed still needed agreement from senior management and the rest of their group of libraries; a different library had not made a decision yet either way, but was waiting to see what other libraries were doing. Most libraries said they would follow what the National Library and other libraries around the country were doing, as they shared records, or downloaded records from Te Puna, and wished to continue doing so. This continued sharing would be unable to happen if the library in question was using a different cataloguing system to the rest of the members in the network.

At the moment, all the public libraries interviewed said it was too early for them to begin making preparations to implement RDA. Some libraries were in the process of talking to management to get their agreement to purchase RDA when it became available, some knew they would be buying it and were just waiting for the pricing to be announced.

From the interviews, the preparations that the libraries are making basically boil down to self-education. Various libraries reported that they were following list servs, along with the e-mails put out by the National Library, 
and reading articles that they had found on RDA. Most libraries had read the draft of RDA, which was published in November 2008, and a couple had attended seminars about RDA held by the National Library (Joint Steering Committee for Development of RDA, 2008).

Heads of Cataloguing are also making sure their cataloguing colleagues or staff know about RDA. Three libraries mentioned making sure senior staff or management know about or have information on RDA. One Head of Cataloguing would e-mail round any articles that they found to their cataloguing staff. For the rest of the library staff, it varied from library to library whether they had any knowledge of RDA. A couple believed most staff would have heard of RDA, if not more than that, but on the main, knowledge of RDA was limited to cataloguing teams and senior staff.

Most libraries were intending to take advantage of the free trial period of the RDA Toolkit, which is available until the end of August 2010, to evaluate it and see how RDA will work and how it will impact cataloguing workflows (American Library Association, Canadian Library Association, \& Chartered Institute of Library and Information Professionals, 2010a). Two libraries mentioned that they had been playing around with RDA. One has been implementing the minor changes that their current library management system (LMS) is able to handle, and another library has a test database that they have been using for some in-house training on RDA. 


\subsection{SUB-QUESTION TWO}

- What would enable New Zealand public libraries to make preparations for RDA?

At the time of the interviews, there were three main sticking points for public libraries before they could think about making preparations for RDA. These were the knowledge of what their supplier of bibliographic records (for example Te Puna or OCLC) was intending to do about RDA, the information on whether their current LMS supported RDA and what their vendor was intending to do about RDA, and the necessity of seeing the final product of the RDA Toolkit before starting to make implementation plans.

A number of libraries acquire their bibliographic records from a larger organisation, such as Te Puna from the National Library or OCLC in the United States. If either of these organisations chooses to implement RDA in the future, then the libraries that download catalogue records from these places will have to change as well. A point to make is that RDA is highly likely to become an international standard. So in order for records to be shared internationally, the various national libraries all need to be using the same system. This means that if the Library of Congress decides to adopt RDA, many other national libraries will follow suit.

Just under half of the Heads of Cataloguing interviewed mentioned that they did not know if their LMS was currently able to support RDA, leaving them unsure if they would need to update their LMS in order to have the ability to 
implement RDA. Many libraries across the country are likely to be waiting on information from their LMS vendors on their decision on supporting RDA, along with whether they will include the changes to MARC21 and the needed updates to indexes that will allow these new sub-fields to be searched and displayed on the catalogue.

All libraries interviewed mentioned the necessity of having a look at the RDA Toolkit before beginning to make their plans for the implementation of RDA. Going through the toolkit will allow Heads of Cataloguing to estimate how much it will change their cataloguing workflows, where AACR2 rules map to in RDA, and what sort of in-house training they might need to devise for their staff. At the time of the interviews, a date for the release of the toolkit had not yet been announced, therefore adding another detail to the list of items that public libraries are waiting on.

\subsection{SUB-QUESTION THREE}

- What are the barriers to and enablers for implementation of RDA for New Zealand public libraries?

One of the most often mentioned barriers to implementing RDA was of public libraries waiting for the National Library to state whether it will be implementing RDA and what the new national standards will be. However, there are more than just the public libraries involved in a waiting game. At the head of the chain are the three American National Libraries (the Library of Congress, the National Library of Medicine and the National Agricultural 
Library) who will be testing RDA for nine months from the release date of the online version (which is expected in June 2010), therefore finishing approximately March 2011 (Library of Congress, 2010). Once these three libraries have released their decision on implementing RDA, it is anticipated that the members of the Joint Steering Committee for the Development of RDA (JSC) will release their decisions. The National Library of Australia has a representative on the JSC; however the National Library does not, putting them one step further away. Once the National Library of Australia has released its decision, the National Library can undertake making its own decision and release that decision to public libraries in New Zealand.

Another often mentioned barrier is budgetary constraints. The cost of subscribing to RDA was a topic of concern, as the equivalent New Zealand price was not known. One library raised the concern that smaller libraries may only be able to afford it by spreading the cost across a group or consortium of libraries. Pricing for the RDA Toolkit was released in a number of major currencies on $16^{\text {th }}$ June 2010 (American Library Association, Canadian Library Association, \& Chartered Institute of Library and Information Professionals, 2010c).

Another cost associated with RDA is that of upgrading to a LMS that will support RDA, if the current system does not. Knowledge of their LMS' ability to support RDA was a fact that just under half the libraries interviewed were unsure of. These libraries are either in the process of upgrading their LMS, or have plans to upgrade. One library was hoping to bring forward their 
LMS upgrade; so as to be ready for RDA sooner, but the Head of Cataloguing was unsure if this would happen.

Every library has a budget, and much forward planning is needed to include any major expenses in a year's budget. For many libraries, this financial year's budget has already been finalised, leaving no spare money available for the subscription to RDA, making it necessary to wait until the next budget cycle for its inclusion.

Another barrier for libraries was, at the time of the interviews, the online version of RDA had not yet been released (this was announced that it was going live on June 232010 (American Library Association et al., 2010b). Many libraries wished to have a look at the final version to see what it was like, before making decisions on whether or not they would recommend their library implement RDA.

One factor that was not an issue with the Heads of Cataloguing that were interviewed was unhappiness or dissatisfaction with RDA. Whilst a number of librarians were sitting on the fence and waiting for the release of the RDA Toolkit before proffering their opinions on whether RDA would do all the things it said it would (for example greater access to collection items and ease of use), on the whole, the librarians believed that RDA was a good thing, and that it was well overdue to happen. As was discussed in the literature review, employees of an organisation are much less likely to be resistant to 
the implementation of a change if they consider it is something that needs to happen.

\subsection{SUB-QUESTION FOUR}

- How does the implementation of RDA compare with the implementation of the Anglo-American Cataloguing Rules $2^{\text {nd }}$ edition (AACR2)?

As none of the libraries interviewed were planning on implementing RDA until the National Library releases their decision on RDA, and as these libraries had not started making any plans for their own implementation, this question is unable to be answered conclusively. However, from the interviews, there are some hints as to how the implementation of RDA may compare with the implementation of AACR2.

From the literature review, five articles on the implementation of AACR2 were found. Elrod $(1979,29-32$.$) gives advice on what smaller libraries in$ five different pre-AACR2-implementation scenarios might do. These scenarios are libraries with a card catalogue only; with a computermaintained card catalogue with unused computer records; with a closed card catalogue supplemented by an online catalogue; with an online catalogue with cumulations made from a retro-converted database; or with an online database. This article suggests that libraries that only have a card catalogue might wish to use guide cards. However, libraries in the other situations may wish to close their card catalogue, update their 
computer records, or, if they have an online database, make the required adjustments to their MARC records.

Woodruff University at Emory University in Atlanta, Georgia carried out a feasibility study to decide on the adoption of LC's policy of implementation of AACR2. By accepting the compatible headings released by LC, the amount of records needing changes was reduced by half. Woodruff Library suggested three ways that the change to AACR2 could be made - interfiling new and old headings, modifying the personal name headings in the card catalogue, or a combination of the two, depending on the size of the file. Findings were that a split file (with 'see also' references) for corporate names would be acceptable, but not one for personal names. Split files would only be considered if it involved moving greater than 200 catalogue cards or retyping greater fifty cards (Kline \& Taylor, 1980, 209-213.).

Once AACR2 came out, libraries worried about how to implement it and what to do with their card catalogues. Most followed the Library of Congress and waited until 1981 to implement it. Small and medium libraries generally chose to interfile the old bibliographic records with the new, while larger libraries either chose to create a new card catalogue and connect it with the old one, or to create a new catalogue and freeze the old one (McIver, 1985, 117-127.).

Some libraries froze their card catalogues and started afresh with a new AACR2-compliant card catalogue. Others chose the path of integration, 
either by filing the new AACR2 headings in with the old (as was suggested in Kline and Taylor (1980, 209-213.)), changing headings over, or by using guide cards. However disruptive to the behind the scenes workings of the library the implementation of AACR2 was, this article makes the point that many library users did not notice the changeover, therefore the disadvantages to AACR2 could not have been as tremendous as predicted (Hepfer \& Hepfer, 1987, 19-25.).

Spangen (1986, 1-6.) described how most Nordic countries used a course and a book of examples in their implementation of AACR2, with a correspondence course or an orientation at their national library also used in some cases. It was anticipated that library users would not greatly notice the changeover to AACR2, but its implementation would enable greater cooperation between libraries.

When asked about the possibility of re-cataloguing their collection to match RDA rules, one library said they would not have the time to do this, however, as they had a relatively small collection, it would be more feasible for them to be able to do this, than other larger libraries. This library did note that they might possibly have to re-catalogue some items (such as digital items or DVDs) so that the records match FRBR terminology and are able to be linked to items higher up the hierarchy. The Head of Cataloguing at this library also mentioned the possibility of updating older records if there was something that needed changing anyway. The thought was that while you 
have it up on your screen, you might as well spend a few extra seconds fixing it up.

As with the change to AACR2 described in Elrod (1979, 29-32.), many libraries are conscious of the need to update their MARC records. However, as all libraries now use computer systems in place of card catalogues, compared with some using computer systems, and some using card catalogues in the time of AACR2, these changes will cause less upheaval.

As both Kline and Taylor (1980, 209-213.) and McIver (1985, 117-127.) reported, most libraries chose to follow the Library of Congress' lead. This has not changed even over a quarter of a century later. Most libraries worldwide are waiting for the results of the testing of RDA by the LC and the three other national libraries in the United States, before making their decisions on the implementation of RDA.

As opposed to the reactions of library patrons to AACR2, who did not notice a thing, it is hoped that library patrons will notice a change once RDA is implemented (Hepfer \& Hepfer, 1987, 19-25.). It is hoped that they will find the library catalogue easier to use and easier to find the item searched for, along with better linking of related works together.

Like in Spangen (1986, 1-6.), it is expected that national libraries will provide training courses on RDA. Whether these courses will take the format of on-site, off-site or online (to compare with the correspondence 
course in Spangen (1986, 1-6.)) or any combination of the three is still not known.

One Head of Cataloguing interviewed did not believe that the change to RDA would necessarily be a huge change. This librarian had looked over the list of changes from AACR2 to RDA and it was their opinion that they seemed to be relatively minor, such as no longer using the abbreviation for edition, and using 'audio' instead of 'sound'. A different Head of Cataloguing said that RDA did not seem to be as great a change as changing to AACR2 was, as libraries now use computer systems instead of card catalogues. However, this librarian mentioned that there would be more formats involved in the change to RDA, instead of just the print and electronic in the day of AACR2.

\subsection{RESEARCH OBJECTIVE}

This research intended to examine how public libraries in New Zealand are planning on implementing RDA. However, public libraries are waiting on the National Library's decision on RDA, and the National Library is waiting on the decisions made by the libraries involved in the testing of RDA and of the members of the JSC.

This research found that libraries do have intentions of implementing RDA. However, they are waiting to see what the National Library will do before fully committing to any plan. Because many libraries share bibliographic 
records with or download records from other libraries, it is necessary that all the libraries on a system are using the same cataloguing rules.

Currently, Heads of Cataloguing are preparing for RDA by trying to educate themselves as much as possible and to keep up with current news about RDA. They are also trying to make sure their cataloguing staff and colleagues along with senior management have this information as well. It is too early for public libraries to be making preparations for RDA for various reasons such as needing management agreement, or the cost of subscribing to RDA.

The free trial period of RDA factors largely into any library's potential RDA implementation plans. This allows librarians to see what RDA is actually like and how it may affect their library.

Three things are holding libraries back from starting to make their RDA implementation plans. One, libraries need to know if their supplier of bibliographic records will be changing to RDA, necessitating that they make the switch as well. Two, libraries need to be sure that their LMS will support RDA; otherwise they may be looking at the expense of upgrading their system. Three, the release of the RDA Toolkit (the online format of RDA). The Toolkit will allow Heads of Cataloguing to see how their daily tasks will be changed and what training they may need to prepare for their staff. 
The most often mentioned barrier to implementation was that of waiting for the National Library to release its decision on RDA. However, this is unlikely to happen until approximately March 2011, when the Library of Congress and the three United States national libraries reach and release their decision on RDA. Once this happens, RDA decisions will trickle out across the world.

Issues relating to budgets also factored largely in librarian's minds. The pricing of RDA was a concern to a number of libraries who worried that smaller libraries would not be able to afford the cost of subscription unless they shared the cost over a group of libraries. The cost of upgrading to an LMS that supports RDA was another issue mentioned. Timing of the release of RDA is an additional budgetary issue, as most libraries will have already finalised their budgets for the 2010-2011 financial year, meaning that any RDA subscriptions will have to wait for the next budget cycle.

Access to the RDA Toolkit kept being mentioned by Heads of Cataloguing. They believed that access to the final product of RDA would facilitate their planning for the implementation of RDA.

All the Heads of Cataloguing interviewed thought that RDA was a muchneeded improvement that should have come out some time ago. It is helpful that dislike of RDA is not creating a barrier to implementation, as the opinions of employees of an organisation are an important factor in whether or not a change will succeed. 
As no libraries are currently implementing RDA, cannot be conclusively compared with the implementation of RDA. However, from the interviews a number of similarities became apparent. As with the change to AACR2, updating of MARC record files is necessary. Although, for RDA, the updates to MARC21 are still being worked upon. Another thing that has not changed since the 1970s is that of the library world looking to the Library of Congress to lead the way in changes to cataloguing rules. As in the 1970s, the library world is waiting with baited breath to see what the Library of Congress will decide about RDA. Unlike the change to AACR2, which went virtually unnoticed by library patrons, the change to RDA is hoped to make library items easier to find and more accessible to library patrons with greater linking between items. Much like what happened with the change to AACR2, national libraries are expected to provide training courses for librarians to aid them in switching over to RDA. One Head of Cataloguing who experienced the change to AACR2 believes that the change to RDA will not be as large as that to AACR2, although it will involve more formats than just paper and electronic.

From the interviews, most Heads of Cataloguing held much the same opinions as each other, but there were two comments that stood out as being completely different to the other responses for those questions. One Head of Cataloguing believed that the changes to RDA did not go far enough in their opinion, and that there was a particular rule that should not have made it into the RDA draft, as there was not any principle in AACR2 that it 
was based on, nor was there one in RDA. This librarian believed that as a supposedly principle-based set of rules, it had not gone far enough.

Another Head of Cataloguing would be very happy to be a trailblazer and be one of the first libraries in New Zealand to implement RDA. This librarian said that they would love to implement RDA, but that it just did not make sense to do so before the National Library, however much they would like to.

Public libraries in New Zealand are not currently planning on implementing RDA. This will come in the near future when the Library of Congress and then the National Library release their decisions on the implementation of RDA. Currently librarians are preparing themselves for RDA by following list servs and e-mails, and by taking advantage of the free trial period of the RDA Toolkit to familiarise themselves with this important new set of cataloguing rules.

In this ensuing nine month period before the Library of Congress announces its decision on RDA, public libraries in New Zealand need to make sure their cataloguing staff are prepared for RDA and that senior management knows about RDA. Libraries need to discover if and when their provider of bibliographic records will be changing to RDA as well as if their current LMS will support RDA, and if not, if and when an upgrade will be available. Libraries need to take as full advantage as possible of the current open access trial of the RDA Toolkit. This will allow librarians to look at the final product, test how it will work, assess how it will impact their library and 
review its advantages and disadvantages in preparation for when it comes time for public libraries to make their decisions on implementing RDA. Public libraries should continue their current efforts on self-education, and also should attend as many training sessions held by the National Library as is practicable.

As with any new change, there will always be people that love the change and people that do not. A number of librarians interviewed were waiting to see the RDA Toolkit before they completely made up their minds on whether RDA would meet its stated goals and librarian's expectations. However, even if it does not meet these goals and expectations in the first release, it is not the end of the world. Like AACR2, RDA can be updated and tweaked in future releases so that it works as well as everybody thinks it should.

The fact that libraries want to be trailblazers for RDA shows that they are excited about RDA and they feel that it cannot come soon enough. Libraries feel that RDA is a much-needed step forward in modernisation. Conversely, this enthusiasm about RDA shows that librarians feel that AACR2 is somewhat outdated for today's technologically-rich world, and that a new set of rules that is easier to understand, flexible and able to deal with new and changing formats and that contains less jargon would be something worth waiting for.

It is hoped that this research will prove of some value to libraries in New Zealand by informing them of what preparations for the implementation of 
RDA public libraries are making. It is hoped that this information will then allow libraries to decide what preparations for RDA they should be making.

\subsection{SUGGESTIONS FOR FURTHER RESEARCH}

This research provides a much-needed contribution to the library and information management field due to the relative newness of RDA. It is because of this newness that there has not been a large amount of research carried out on this subject, a fact that this research aims to change in some small part. It is further hoped that this research will motivate future indepth studies in this field.

This research is ripe to be picked up and carried on by a researcher in the not too distant future when the Library of Congress, the National Library of Medicine, the National Agricultural Library, the JSC and the representatives to the JSC are closer to releasing their statements on whether or not they will implement RDA. It is due to the length of the testing process, carried out by the three American national libraries, which will start once RDA is released, and the necessity of waiting for various major library organisations around the world to release their decisions, that no public libraries have started making any plans for the future implementation of RDA. Due to these facts, I believe this research would have obtained better and more conclusive results to the research questions posed, if it had been carried out at a later date. 
As mentioned in the limitations section above, a larger sample size over a larger geographic area and the inclusion of academic and special libraries along with public libraries that this study covered may increase the transferability of this research.

\subsection{REFERENCES}

Adamich, T. (2008). RDA (Resource Description and Access: The new way to say "AACR2". Knowledge Quest, 36(4), 64-69.

American Library Association, Canadian Library Association, \& Chartered Institute of Library and Information Professionals. (2006a, n.d.). About AACR2.

Retrieved 27 June, 2010, from http://www.aacr2.org/about.html

American Library Association, Canadian Library Association, \& Chartered Institute of Library and Information Professionals. (2006b, n.d). Anglo-American

Cataloguing Rules second edition, 2002 revision: 2005 update. Retrieved 27 June, 2010, from http://www.aacr2.org/australia/products aacr2.html

American Library Association, Canadian Library Association, \& Chartered Institute of Library and Information Professionals. (2006c, n.d). Online Access. Retrieved 27 June, 2010, from http://www.aacr2.org/access.html

American Library Association, Canadian Library Association, \& Chartered Institute of Library and Information Professionals. (2010a, n.d.). Complimentary openaccess period. Retrieved 27 June, 2010, from http://www.rdatoolkit.org/openaccess

American Library Association, Canadian Library Association, \& Chartered Institute of Library and Information Professionals. (2010b, 23 June). It's here! The RDA 
Toolkit launches Wednesday, June 23. Retrieved 27 June, 2010, from http://www.rdatoolkit.org/news/launch

American Library Association, Canadian Library Association, \& Chartered Institute of Library and Information Professionals. (2010c, 16 June). RDA Toolkit pricing and subscribing, wherever you are. Retrieved 27 June, 2010, from http://www.rdatoolkit.org/news/globalpricing

American Library Association, Canadian Library Association, \& Chartered Institute of Library and Information Professionals. (2010d, 28 April). RDA Toolkit solo-user Pricing, double-user offer, and RDA print. Retrieved 27 June, 2010, from http://www.rdatoolkit.org/solouser

Baby-Friendly USA. (2010, n.d.). BFHI USA. Retrieved 27 June, 2010, from http://www.babyfriendlyusa.org/eng/index.html

Bryman, A. (2008). Social Research Methods (3rd ed.). Oxford: Oxford University Press.

Buckle, D. (1986). AACR2 implementation five years on. Catalogue \& Index, 80, 1-5.

Chien, T.-K., Su, C.-H., \& Su, C.-T. (2002). Implementation of a customer satisfaction program: A case study. Industrial Management \& Data Systems, 102(5), 252259.

Conners, D. (2008). A ghost in the catalog: The gradual obsolescence of the main entry. The Serials Librarian, 55(1), 85-97.

Coyle, K., \& Hillman, D. (2007). Resource Description and Access (RDA): Cataloging rules for the 20th century [Electronic Version]. D-Lib Magazine, Retrieved 27 June 2010, from http://www.dlib.org/dlib/january07/coyle/01coyle.html.

Elrod, J. M. (1979). Desuperimposition, AACRII, and the smaller library catalogue. Cataloguing Australia, 5(3), 29-32. 
Ferguson, A. W. (2007). Managing change in the Hong Kong library environment. Library Management, 28(8/9), 524-530.

Fullerton, J. (1979). Implementation of AACR2 in National Bibliographic Services. Cataloguing Australia, 5(4), 13-25.

Gorman, M. (1978)....And now, from the wonderful folks who gave you superimposition. American Libraries, 9(10), 620-621.

Gorman, M. (1987). Implementing changes in cataloging rules. Library Journal, 112(3), 110-112.

Gorman, M. (2007). RDA: Imminent debacle. American Libraries, 38(11), 64-65. Hepfer, C., \& Hepfer, W. (1987). AACR2's effect on public services. The Serials Librarian, 12(1), 19-25.

Hillman, D. (2009,18 July). FRBR vs. FRBR-ization Message posted http://managemetadata.org/blog/2009/07/18/frbr-vs-frbr-ization/.

Joint Steering Committee for Development of RDA. (2005, 1 July 2009). RDA: Resource Description and Access prospectus. Retrieved 27 June, 2010, from http://www.rda-jsc.org/rdaprospectus.html

Joint Steering Committee for Development of RDA. (2008, 1 November). RDA:

Resource Description and Access - Constituency review of full draft.

Retrieved 27 June, 2010, from http://www.rda-jsc.org/docs/5rda-fulldraftcover.pdf

Joint Steering Committee for Development of RDA. (2009, 1 July). A brief history of AACR. Retrieved 27 June, 2010, from http://www.rda-jsc.org/history.html Joint Steering Committee for the Development of RDA. (2010, 18 January). RDA: Resource Description and Access frequently asked questions. Retrieved 27 June, 2010, from http://www.rda-jsc.org/rdafaq.html 
Jones, E., \& Carr, P. L. (2007). The shape of things to come: Resource Description and Access (RDA). The Serials Librarian, 52(3), 281-289.

Kline, P. S., \& Taylor, M. R. (1980). Adapting an existing card catalog to AACR2: A feasibility study. Library Resources \& Technical Services, 24(3), 209-213.

Library of Congress. (2010, n.d.). Tentative timeline for U.S. National Libraries RDA test. Retrieved 27 June, 2010, from http://www.loc.gov/bibliographic$\underline{\text { future/rda/timeline.html }}$

Mclver, C. (1985). The AACRs and serials cataloging. The Serials Librarian, 10(1), 117-127.

Merewood, A., \& Philipp, B. L. (2001). Implementing change: Becoming BabyFriendly in an inner city hospital. Birth, 28(1), 36-40.

Moore, J. R. (2006). RDA: New cataloging rules, coming soon to a library near you! Library Hi Tech News, 9, 12-16.

Needleman, M. (2008). The Resource Description and Access standard. Serials Review, 34, 233-234.

Osborn, A. (1979). The professional excellence of AACR2: Its implementation in Australia. Australian Library Journal, 28, 301-304.

Paton, B., Beranek, L., \& Smith, I. (2008). The transit lounge: A view of organisational change from a point in the journey. Library Management, 29(1/2), 87-103.

Simonton, W. (1979). An introduction to AACR2. Library Resources \& Technical Services, 23(3), 321-339.

Spangen, I. C. (1986). Implementation of AACR2 in the Nordic countries. Catalogue \& Index, 81, 1-6. 
Tennant, R. (2007). Digital libraries: Will RDA be DOA? [Electronic Version]. Library Journal, Retrieved 27 June 2010, from http://www.libraryjournal.com/article/CA6422278.html.

Wells, A. (2007). A prototype twenty-first century university library. Library Management, 28(8/9), 450-459. 


\section{Participant Information Sheet}

Preparations for implementation of RDA in New Zealand public libraries

Researcher: Chloe Turner: School of Information Management, Victoria University of Wellington

I am a Masters student in Library and Information Science at Victoria University of Wellington. As part of this degree I am undertaking a research project. The aim is to investigate what preparations for the implementation of RDA public libraries are making. The University requires that ethics approval be obtained for research involving human participants.

I am inviting Heads of Cataloguing working at public libraries to participate in this study. Participation is entirely voluntary. Participants will be asked to take part in an interview made up of open-ended questions aimed at gathering the views and opinions of the individual. It is envisaged that the interview will take about an hour to complete. I would like to make an audio recording of the interview session to be used to verify that my written notes are correct.

Should any participants feel the need to withdraw from the project, they may do so without question at any time before Sunday 18 April. Any information provided up to that point will not be used in the project and will be destroyed.

Responses collected will form the basis of my research project and will be put into a written report on an anonymous basis. All material collected will be kept confidential. No other person besides my supervisor, Dr Dan Dorner, and me will see the interview notes. Interview notes and similar materials will be destroyed two years from the date of project completion, however, interview recordings will either be returned to the participant, or wiped at the end of the project. Participants will also have an opportunity to check their transcripts. Participant may choose to receive a summary of the research results upon completion of the project. 
The research project will be submitted for marking to the School of Information Management and a copy deposited in the University Library. The results of the study may be used for publication in academic or professional journals or dissemination at academic or professional conferences. Any further use of the information will require the participant's written consent.

If you have any questions or would like to receive further information about the project, please contact me at (04)801 4057 or turnerchlo@myvuw.ac.nz or my supervisor, Dr Dan Dorner, at the School of Information Management at Victoria University, P O Box 600, Wellington, phone 04 463-5781, or by e-mail at dan.dorner@vuw.ac.nz

Chloe Turner

Signed:

\section{VICTORIA UNIVERSITY OF WELLINGTON CONSENT TO PARTICIPATION IN RESEARCH}

\section{Title of project: Preparations for implementation of RDA in New Zealand public libraries}

I have been given and have understood an explanation of this research project. I have had an opportunity to ask questions and have them answered to my satisfaction. I understand that I may withdraw myself (or any information I have provided) from this project before Sunday 18 April without having to give reasons or without penalty of any sort.

I understand that any information I provide will be kept confidential to the researcher (Chloe Turner) and the supervisor (Dr Dan Dorner), the published results will not use my name or the name of my organisation, and that no opinions will be attributed to me in any way that will identify me. I understand that the tape recording of interviews will be electronically wiped at the end of the project unless I indicate that I would like them returned to me, and I understand that I will have an opportunity to check the transcripts of the interview before publication.

I understand that the data I provide will be used only for this research, publication in academic or professional journals or dissemination at academic or professional 


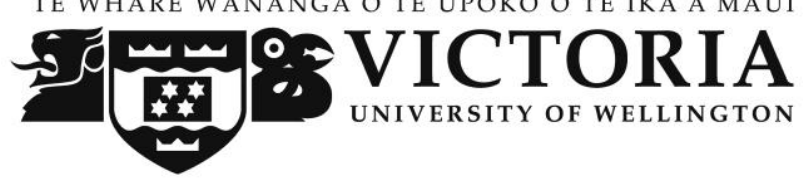

conferences. It will not be used for any other purpose or released to others without my written consent.

$\square$ would like my interview tape to be returned to me.

$\square$ would like to receive a summary of the results of this research when it is completed.

$\square$ agree to take part in this research

signed:

name of participant

(please print clearly)

Date: 


\subsection{INTERVIEW GUIDE}

- How do you feel about RDA?

- Do you believe it will improve access to library items?

- Do you think it will work better for cataloguing digital items?

- Why/why not?

- What sort of impact do you think it will have on cataloguing at this library?

- How did you make your decision to change to RDA?

- Did you consider any alternatives?

- Why/why not?

- Do you have a plan for how you're going to manage the change to RDA?

- What is in your plan?

- If not (no change management plan), why not?

- Do you intend to make sure staff know why this change needs to happen?

- If there are any people who are not happy about the change, how will you deal with those people?

- What are some of the other preparations that you have made for the implementation of RDA?

- What caused you to make these preparations?

- What barriers are there to you making preparations?

Is there anything else that you feel is important that you wish to add?

If necessary, ask:

- Do you intend to nominate change champions?

- Ensure staff feel involved in the change?

Keep staff informed of how the change is progressing? 
10,248 words 